\title{
EFFECT OF WATER PH ON DOMESTIC MACHINE WASHING PERFORMANCE OF DELICATE TEXTILES
}

\author{
Nilüfer Çakmakçı1*, Cevza Candan², Başak İlkiz Arslan³ \\ 1 Department of Organic Materials and Fiber Engineering, Soongsil University, Seoul 06978, Korea \\ 2 Istanbul Technical University, Textile Technologies and Design Faculty, Department of Textile Engineering \\ 3 Arçelik Incorporation, Department of Product Training, HQ, Sütlüce, 34445 ISTANBUL \\ ${ }^{*}$ Corresponding author: nlfrckmkci@gmail.com
}

\begin{abstract}
:
In order to investigate the effect of washing water $\mathrm{pH}$ on textile damage for delicate garments, the study was conducted such that a customer survey was first applied to randomly selected users to analyze domestic washing machine using habits of Turkish consumers. Based on the findings of the survey, the experimental study was designed in two successive phases to investigate the dimensional and mechanical behavior of certain types of delicate textiles against varying washing conditions by taking in particular, water properties, namely $\mathrm{pH}$, hardness, and temperature into account, and accordingly to determine the optimized washing conditions for such textiles. Firstly, tergotometer was employed as a washing machine simulator. Within the light of the results obtained, the experimental work of the second phase of the study was conducted, which involved a domestic washing machine as a real-life scenario. All of the results, including the correlation between the data sets obtained from the tergotometer and domestic washing machine trials, were statistically analyzed using Minitab 17. The study produced some important findings regarding the effect of washing water $\mathrm{pH}$ on delicate textiles, in addition to an algorithm for improving the present washing program, minimizing textile damage for mainly wool and silk garments.
\end{abstract}

\section{Keywords:}

Domestic washing machine, water $\mathrm{pH}$, tergotometer

\section{Introduction}

Washing of clothing in domestic laundering machines is influenced by physicochemical and mechanical actions. The physicochemical action plays a role in separating soil from clothes and dispersing it into the detergent solution, whereas the mechanical action facilitates separating soil from textiles by flexing and inducing friction between textiles, moving loosened soil to the detergent solution, and delivering fresh detergent solution to the textile surfaces [1-4]. Based on the classification of the mechanical actions of washing (i.e. large-scale, smallscale, and molecular scale), movements in a washer are large-scale and small-scale effect, and affect textiles in terms of tensile strength and shearing stress by textile flexing and detergent flux $[3,5]$. So, the control of these forces for an effective washing in a washer is mainly regulated by the parameters of wash spin speed, on/off time of motor, washing time, and water amount $[3,4,8-13]$. However, the wet rubbing and beating operations essential to effective cleaning are partly responsible for the deterioration in textiles that have been washed. The fabric changes that occur during washing, such as shrinkage, distortion, fiber damage, fabrics becoming stiff and harsh, color fading, and cross-staining by fugitive dyes, are all also dependent on fiber type, fabric construction, dye class, and the fabric finishing processes applied and production method.
Over the years, innovation drives the apparel market providing consumers with an increasing array of products to choose from, including the products that are made from established luxury fibers namely silk and wool and their blends, but are used in non-traditional ways such as next-to-skin knitwear and/or various types of much lighter garments for trans-seasonal daily wear. In addition to that, the modern lifestyle has created an increased consumer demand for machine washability of almost all textiles, including the delicate ones [14]. Obviously, delicate textiles are more susceptible to the aforementioned mechanical actions in a washer than the others, i.e. cotton, linen garments, etc. Silk textiles, for example, crease and dimensionally deform easily during conventional home laundering [15]. Wool, on the other hand, is a unique fiber and the only one that has a tendency to shrink or "felt" due to unidirectional external forces when agitated in the presence of water [16]. Literature offers several alternative studies on damage-free cleaning solutions for delicate textiles such as silk [1,3,15,18-21], and some more on laundering conditions of wool from the perspective of felting. Those studies show that in domestic washing machines, variations in the $\mathrm{pH}$ and temperature of the solutions can cause large differences in felting rates, especially of wool made shrink resistant by oxidation procedures, and that in general, felting rate of treated wool decreases with increasing $\mathrm{pH}$ and temperature of the solutions, the relative effects of given changes in the composition of the solution usually being greater with treated than untreated wool [20,22]. Also, 
for improved wash-and-wear appearance of various types of textiles, there are many researches focused on the influence of washing conditions (i.e. water temperature, agitation, etc.), including hygiene related factors, in addition to the gentle action appliances developed by machine manufactures as well as the introduction of more effective detergent systems that ensure the removal of soil and stains without the robust mechanical action of traditional washing machines $[9,14,19,23-$ 26]. However, in these studies, water quality is mostly limited with water hardness, and to the best of our knowledge, there is lack of representative data available regarding the effect of wash (detergent + water solution) $\mathrm{pH}$ on textile damage in the laundry process, despite the fact that it may cause deterioration in wool/silk-based textiles by repeated washing and/or elevate desorbed dye increase in the bath as a result of detergent selection, changing consumer laundry habits, and/or combination of both [26,30-39].

Accordingly, the current study was conducted: a) to systematically examine the influence of water $\mathrm{pH}$, together with the other washing parameters, on textile wear. In doing so, particular attention was given to textiles from specialty protein fibers such as silk and wool, as they are becoming increasingly popular for products intended for every-day consumer use; b) to investigate if tergotometer can be used as a laundering simulator for delicate textiles; and finally, c) to collect data on laundering performance of delicate textiles for improving hand wash and/or wool programs for domesting laundering machines as further work.

\section{Experimental}

As a base for the experimental design of the study, a survey was conducted using a structured questionnaire to identify Turkish consumers' laundry habits, including cleaning behaviors toward delicate textiles. The survey was applied, face-to-face, to the participants who were randomly chosen from the pool of domestic washing machine users living in different districts of İstanbul. The regions for the survey were determined such that they were the most populated areas in İstanbul, having the people coming from diverse economic and cultural backgrounds. After the questionnaires of nonconsistent respondents were eliminated, the results obtained for 291 participants (201 females and 90 males) were taken into account for subsequent analysis. The discussion of the analysis is out of the scope of the current study. However, the most important results regarding the experimental design devised for the current study are given as follows:

1. $64 \%$ of the participants prefer domestic laundering machines to wash their delicate textiles (wool, cashmere, etc.).

2. $41 \%$ of the participants do avoid using the domestic washing machines for silk garments.

3. For the majority of the respondents, washing temperatures of 30 and $20^{\circ} \mathrm{C}$ are the most popular ones so far as delicate textiles are concerned.

4. For delicate textiles, $57 \%$ of the participants use a wool/ silk washing program, whereas $40 \%$ prefer the "hand wash" washing program in the machines.

5. The main problems faced by the participants are pilling and dimensional changes for wool textiles, whereas it is the wrinkling and loss of texture for silk textiles.

6. The quality and type of detergent are perceived as having a critical impact on garment quality, and accordingly, for preventing textile damages, including the delicate ones, $59.8 \%$ of the participants use liquid detergents.

In light of these findings, the material and method of the study were detailed and are given in the following sections.

\subsection{Materials}

For the study, three different fabrics made from wool and silk were used as test samples. Table 1 presents the general properties of the test samples used. All test sample fabrics did not have any special finishes, and they were conditioned at $55 \% \pm 5$ relative humidity and $23^{\circ} \mathrm{C} \pm 2^{\circ} \mathrm{C}$ temperature for 24 hours before the textile quality tests were conducted.

The test sample-1 is used for testing the dimensional performance of knitted wool textiles in accordance with ISO 6330:2012 Textiles - Domestic washing and drying procedures

Table 1. Properties of the test samples

\begin{tabular}{|c|c|c|c|c|}
\hline Test sample type & Raw material & $\begin{array}{c}\text { Fabric construction } \\
\text { and design }\end{array}$ & $\begin{array}{c}\text { Basis weight } \\
\text { of fabric }\end{array}$ & Certification \\
\hline Test sample-1 & $\begin{array}{c}100 \% \text { high- } \\
\text { quality Merino } \\
\text { Wool }\end{array}$ & $1 \times 1 \mathrm{rib} \mathrm{knit}$ & $273 \mathrm{~g} / \mathrm{m}^{2}$ & $\begin{array}{c}\text { Supplied from AWI (Australian Wool } \\
\text { Innovation Ltd.). Used for Woolmark } \\
\text { Apparel Care Certification of Tumble Dryers }\end{array}$ \\
\hline Test sample-2 & $100 \%$ wool & Plain weave & $138 \mathrm{~g} / \mathrm{m}^{2}$ & $\begin{array}{r}\text { Supplied from Swissatest, Sample Code } \\
318 \text { Wool Shrinkage Test Fabric IWS-Wool } \\
\text { SM-12 Test Cloths }\end{array}$ \\
\hline Test sample-3 & $100 \%$ silk & Plain weave & $67 \mathrm{~g} / \mathrm{m}^{2}$ & Custom-made for the study \\
\hline
\end{tabular}


for textile testing. For the work, it was selected to simulate reallife knitted wool garments such as jumpers and scarves.

The test sample-2 is employed as standard wool fabric for testing the dimensional performance of woven wool textiles in accordance with BS EN 60456:2011 Clothes washing machines for household use - Methods for measuring the performance. This woven wool fabric sample was utilized as a representation of woven wool garments/accessories such as pants and skirts.

$100 \%$ silk woven fabric, which is coded as test sample- 3 in Table 1 is concerned, was supplied from a local silk fabric producer as there is no standard silk fabric for testing textiles in domestic washing machines. The structural properties of the fabric (the warp density is 28 ends/cm and weft density is 26 picks/cm, the yarn linear density is 13 tex without no twist) were determined such that they were as close as to those of the silk textiles such as silk scarfs, blouses, and shirts washable in domestic laundering machines. Moreover, because 100\% knitted silk garments are very rare in the market, only woven silk fabrics were used for the work.

For domestic washing machine tests, polyester base load fabrics are used to achieve a maximum load of washing program of $2 \mathrm{~kg}$. The details of the base load can be found in ISO 6330:2012 Textiles - Domestic washing and drying procedures for textile testing standard base load.

For evaluating the washing performance of woolen programs, standard stain strips from Swissatest specially designed for use in washing machines were employed.

There are four stained standard wool fabrics (namely red wine, chocolate milk, blood, and carbon black stain) and one control fabric on the lacquer strip. To assess washing performance in accordance with BS EN 60456 - Clothes washing machines for household use - Methods for measuring the performance, tristimulus $Y$ reflectance measurements are carried out on each of the individual soil types and the unsoiled test piece, which makes up the stain test strip. Reflectance measurements are taken of the same washed soil type [40].

For the work, a commercially available liquid laundry detergent from the detergent market was selected based on the findings obtained from the questionnaire mentioned above.
For the experimental work, the water was conditioned in accordance with EN 60734:2012- Household electrical appliances. Performance. Water for testing standard. The process may be summarized as follows: The tap water was taken from the water supply network and treated in a reverse osmosis unit to transform pure water in a vessel. After that, the water was transported to another vessel for chemical dosing so that the water hardness of $15-16{ }^{\circ} \mathrm{dH}$ German values and $\mathrm{pH}$ value of 7.0 could be achieved. In order to eliminate the detergent effect on $\mathrm{pH}$, which is known as a dominant factor, detergent was first added into wash liquor, and then, the desired $\mathrm{pH}$ values of the water (i.e. 6.0, 7.5, and 9.0) was regulated using $\mathrm{HCl}$ and $\mathrm{NaOH}$.

\subsection{Equipment and Devices}

Washing Equipment and Programs: For the washing tests, both tergotometer from Copley Scientific which is used to simulate of domestic washing machine in small-scales, similar to the applications in the literature and a domestic washing machine for the real-life scenario were employed $[4,6,31,41]$.

The tergotometer has a single-drive mechanism that stirs eight reservoirs simultaneously, and the temperature is adjustable. All reservoirs have $1,000 \mathrm{~mL}$ liquid capacity. The temperature can be raised up to $70^{\circ} \mathrm{C}$, and the speed (rpm) is within the range of 50 to $200 \mathrm{rpm}$. For the study, the speed of the tergotometer was set to $52 \mathrm{rpm}$, and the whole capacity, namely $1,000 \mathrm{~mL}$, was utilized. The domestic washing machine used, on the other hand, was a front-loading type with a capacity of $9 \mathrm{~kg}$, and the spin speed of the wool washing program was $800 \mathrm{rpm}$ (see Table 2).

The washing data of the wool program in the domestic washing machine (i.e. temperature from inside of both the drum and heater, rotation of the drum, water intake amount, power, energy, current, volt, and time) are given in Figure 1-a, collectively. The details of the hand wash program selected for silk samples, however, are presented in Figure 1-b.

Similar to the wool washing program, the mechanical effect was at the lowest level in the hand washing program. The main wash water amount was the same as the wool program, which was $11 \mathrm{~L}$. Also, the water amount for the first rinse step was 10 $L$, whereas it was $12 L$ for the second rinse step.

Table 2. Washing Equipment Settings

Tergotometer

\begin{tabular}{|c|c|c|c|}
\hline Test Step & Duration $(\mathbf{m i n})$ & Temperature $\left({ }^{\circ} \mathbf{C}\right)$ & Rpm \\
\hline Main wash & 30 & 30,40 & 52 \\
\hline $1^{\text {st }}$ rinse & 5 & 20 & 52 \\
\hline $2^{\text {nd }}$ rinse & 5 & 20 & 52 \\
\hline
\end{tabular}

Washing Machine

\begin{tabular}{|c|c|c|c|}
\hline Wool program & $\mathbf{5 8}$ & $\mathbf{4 0}$ & $\mathbf{3 5}$ \\
\hline Hand washing program & 41 & 40 & 45 \\
\hline
\end{tabular}




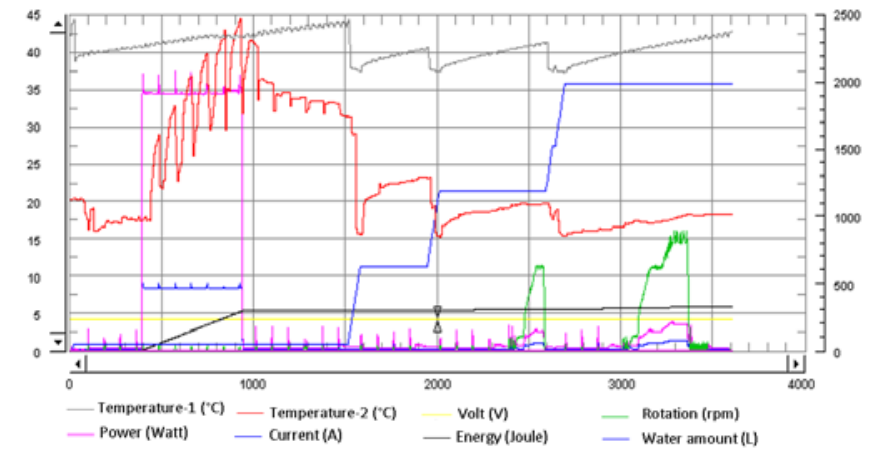

A. Wool program.

Figure 1. The details of wool (a) and hand wash (b) programs

For water measurements; $\mathrm{pH}$ meter, water hardness kit, and water conductivity meter were used, whereas for the fabric measurements Datacolor Spectrophotometer, bursting strength tester, and textile tensile strength tester were utilized. The measuring devices are listed below:

- Water pH measurement: Mettler Toledo, S220-KIT pH/lon Seven Compact.

- Water conductivity measurement: HACH, HQ40d.

- Water hardness measurement: $\mathrm{HACH}$, Total hardness test kit model 5-B.

- Spectrophotometer device for color measurement of wool and silk fabrics: Datacolor 600 Spectrophotometer. Spectrophotometer was also used for reflectance measurements of wool stain strips.

- Measurement of tear strength of woven wool and woven silk fabrics: Titan2 - Universal Strength Tester Machine.

- Measurement of bursting strength: PnuBurst ${ }^{\mathrm{TM}}$ Pneumatic Bursting Strength Tester.

\subsection{Method}

The designs of an experiment for the two phases of the study, i.e. small-scale tests (tergotometer) and real-life scenarios (domestic washing machine), were done at two washing temperatures $\left(30^{\circ} \mathrm{C}\right.$ and $\left.40^{\circ} \mathrm{C}\right)$ and different $\mathrm{pH}$ values. Three $\mathrm{pH}$ values were selected to simulate acidic $(\mathrm{pH} \mathrm{6)}$, real-life scenario $(\mathrm{pH} 7.5)$, and basic condition $(\mathrm{pH} 9)$ for both tergotometer and domestic washing machine tests.

For tergotometer tests, Sample-1 (knitted wool fabric), Sample-2 (woven wool fabric), and Sample-3 (woven silk fabric) were washed separately at $30^{\circ} \mathrm{C}$ and $40^{\circ} \mathrm{C}$, and three different $\mathrm{pH}$ values $(\mathrm{pH} \mathrm{6,} \mathrm{pH} 7.5$, and $\mathrm{pH}$ 9). For domestic washing machine tests, because there is wool program in the machine, Sample-1 (knitted wool fabric) and Sample-2 (woven wool fabric) were washed together with the recommended wool program, while Sample-3 (woven silk fabric) was washed separately with the recommended hand wash program. All

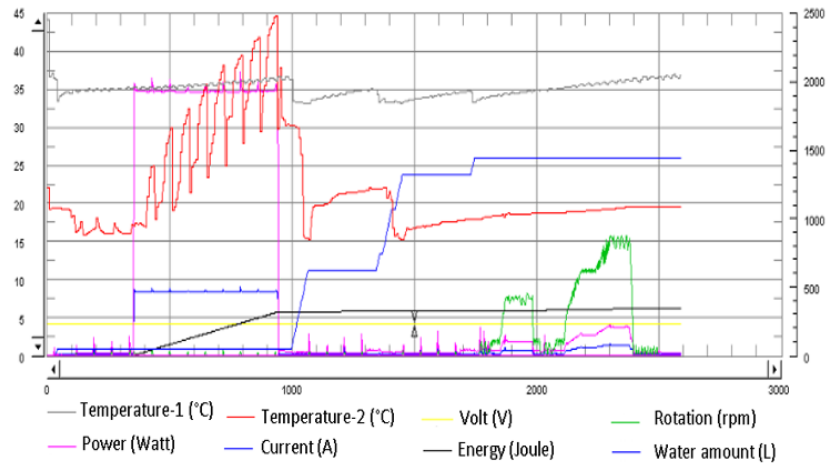

B. Hand wash program.

domestic washing machine testes were done at $40^{\circ} \mathrm{C}$ and three different $\mathrm{pH}$ values $(\mathrm{pH} 6, \mathrm{pH} 7.5$, and $\mathrm{pH}$ 9).

The design of experiment for the real-life scenario (i.e. domestic washing machine tests) was conducted in accordance with the data obtained from the tergotometer tests. The spin cycle, wash time, and water intake values of the washing programs (i.e., wool and hand wash programs) were kept constant.

Tergotometer tests were repeated 10 times for each condition to simulate 10 consecutive washing cycles in real life. In tergotometer tests, after the first, fifth, and tenth washes, the dimensional stability and color change performance of the samples were tested. Also, the washing water parameters, namely water $\mathrm{pH}$ value, hardness, and conductivity, were measured before and after each wash in tergotometer tests to keep the parameters of tergotometer washing system under control. In addition to these measurements, the tear strength and bursting strength of the samples were tested at the end of the fifth as well as the tenth wash.

When it comes to washing machine tests, at the end of the first and fifth washes, dimensional change measurements were repeated. Adding to these measurements, after the fifth cycle color measurements, tear strength and bursting strength were measured. Similar to the tergotometer washing tests, the washing machine water characteristics (i.e., water hardness, $\mathrm{pH}$ value of water, and water conductivity) were also continuously kept under control.

All the results were statistically analyzed using Minitab 17 statistical software and using ANOVA, which is analysis of variance, to find out the effect of parameters on dimensional change, tearing, and bursting strength for tergotometer tests. In addition to that, two-way interactions of the main parameters and the main effects of these parameters were also studied for tergotometer tests. Moreover, the correlation between the data collected from the tests using tergotometer and domestic washing machine were analyzed in order to investigate if tergotometer can be used as a simulation device of the washing machine to reduce water and textile material waste.

Following the statistical analysis of the data collected from the samples laundered using two different washing devices, namely tergotometer and domestic laundering machine, the 
correlation analysis is performed between these two sets of the data for each parameter (i.e., bursting strength, tearing strength, and dimensional change) using Minitab software.

\section{Results and Discussion}

\subsection{Dimensional Stability}

ANOVA analysis showed that the variables $\mathrm{pH}$ value, number of washing cycle, temperature, and sample type are influential for dimensional change (the $p$ values $\leq 0.05$ ) and the R-square for statistical analysis of dimensional stability was $96.02 \%$. Adding to this, the two-way interactions were 0.006 for $\mathrm{pH}$ value washing cycle, 0.000 for washing cycle - water temperature, 0.000 for washing cycle - sample type, and 0.007 for water temperature - sample type.

Furthermore, the distribution of the effective parameters (for tergotometer tests) on dimensional change revealed that the number of washing cycles $(44.5 \%)$ is the most significant factor, which is followed by sample type (34 \%) and temperature (6.8 $\%)$. The effect of the $\mathrm{pH}$ value of the washing water, however, is $1.9 \%$. The ANOVA also suggested that irrespective of the sample type (i.e., knitted or woven), dimensional change increases as the water $\mathrm{pH}$ value, washing cycles, and temperature increase. Two-way interactions of the relevant data demonstrated that the effect of both $\mathrm{pH}$ value and water

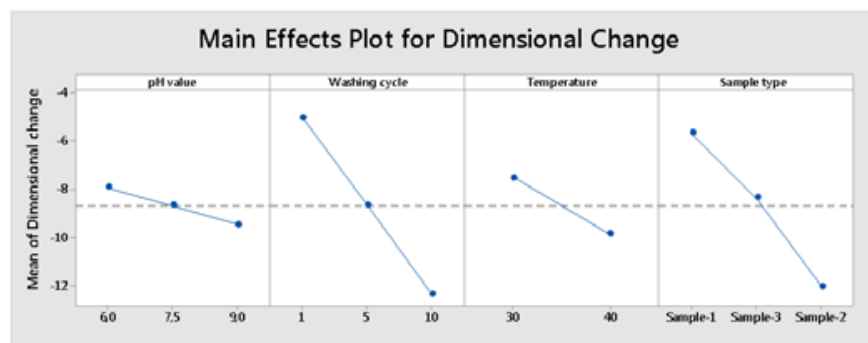

Figure 2. Main effects of dimensional stability.

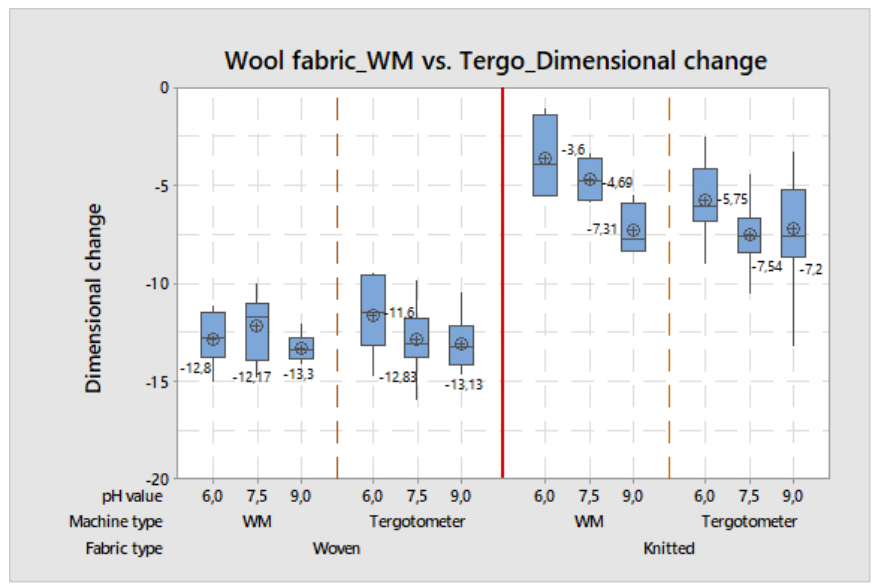

A. Woven and knitted wool fabric temperature on dimensional change become more significant as the number of washing cycles is increased.

As the $\mathrm{pH}$ level decreases, the dimensional change decreases, and the tendency is very similar for washing machine and tergotometer, as given in Figure 3.

Finally, so far, as both of the washing equipment (tergotometer and domestic washing machine) used for the work are concerned, the statistical analysis of each sample leads to the fact that relatively lower $\mathrm{pH}$ levels of washing water are needed for better dimensional stability (see Figures 2 and 3).

\subsection{Tearing Strength}

The tearing strength results in both warp and weft directions of the woven wool and silk fabrics were statistically analyzed and the R-square value was $93.52 \%$. The ANOVA test results revealed that each parameter as well as their two-way interactions have an influence on tearing strength performance of the relevant samples (i.e., Samples 2 and 3); the p value for all main factors, which are sample type, temperature, $\mathrm{pH}$ value, and washing cycle, were 0.000 , and the $p$ value of two-way interactions was 0.011 for sample type $-\mathrm{pH}$ value and 0.001 for water temperature - washing cycle.

The results and statistical analysis for both warp and weft directions have a similar pattern. For simplicity purposes, only the results obtained from the warp directions are discussed in this article. The distribution of the effective parameters on the tearing strength performance of the samples demonstrated that irrespective of the measurement direction (i.e. warp and weft), the sample type (see Table 1) is the most effective parameter $(76.6 \%)$, which is followed by the number of the washing cycles (11.1\%). The effect of the $\mathrm{pH}$ value of the washing water is, on the other hand, found to be more significant in the warp direction $(2.5 \%)$, when compared to the effect on the weft direction (1\%).

Figure 3. Dimensional change of (a) woven and knitted wool fabric, (b) woven silk fabric in warp direction after 5 washes at $40^{\circ} \mathrm{C}$ in tergotometer versus washing machine

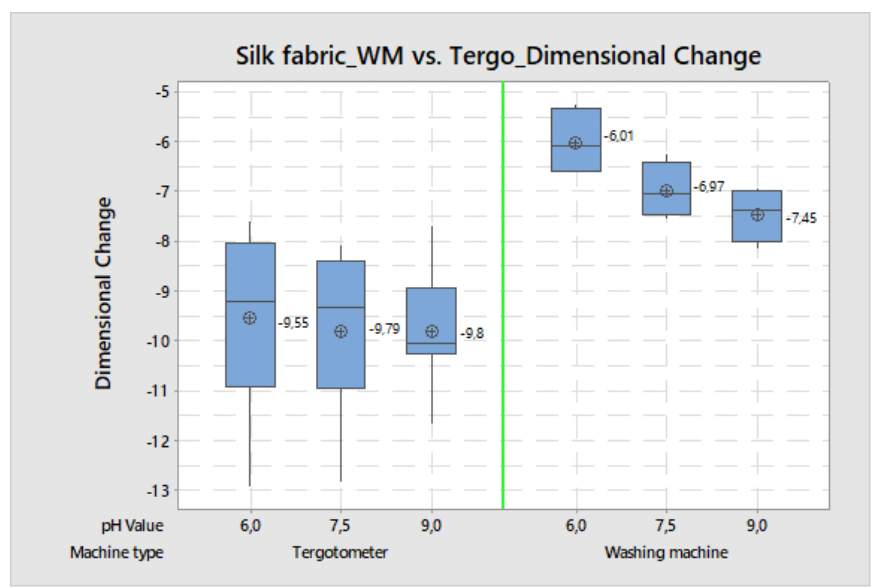

B. Woven silk fabric. 


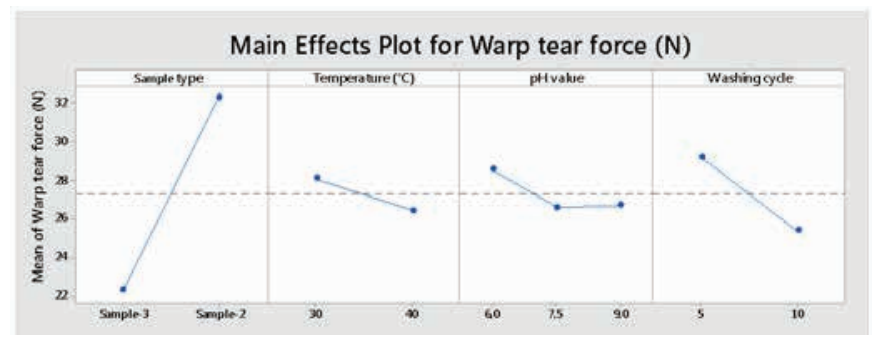

Figure 4. Main effects plot for tearing strength in warp direction

As given in Figure 4, the further statistical analysis of the main parameters suggested that the tearing strength in both directions decreases when temperature, number of washing cycles, and the $\mathrm{pH}$ value of washing water does increase. Moreover, the results obtained implied that the tearing strength tends to slightly drop when the wash $\mathrm{pH}$ is set at the value of 7.5 (see Figure 4).

Finally, after five washes at $40^{\circ} \mathrm{C}$ using a domestic laundering machine, the tearing strength performance of the samples is similar to that of the samples washed using tergotometer (see Figure $5(a-b))$.

\subsection{Bursting Strength}

This evaluation involves Sample 1 - knitted wool only. The R-square value was $86.07 \%$, together with the $p$ values ( $\leq$ 0.05 ), which demonstrated that each parameter, including their two-way interactions, affects the bursting strength performance of the relevant sample. All main factors (temperature, $\mathrm{pH}$ value, washing cycle) and the two-way interaction of the water temperature-washing cycle have 0.000 as a $p$ value. Also, the $p$ value for the two-way interaction of the water temperature$\mathrm{pH}$ value was 0.003 , and for the two-way interaction of the $\mathrm{pH}$ value-washing cycle was 0.011 .

Furthermore, the number of washing cycles is the most effective parameter $(51.7 \%)$, which is followed by the $\mathrm{pH}(14.9 \%)$ and the temperature $(10.6 \%)$. So far, as the two-way interactions

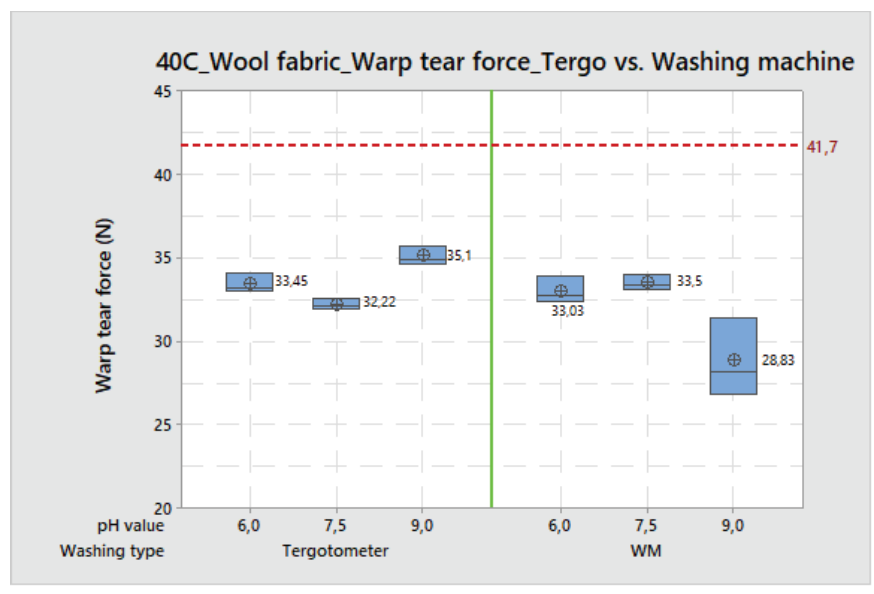

A. Woven wool fabric are concerned, it is the temperature and number of washing cycle interaction that is the most significant one, with $7.2 \%$. The statistical analysis of the main parameters revealed that the bursting strength decreases when the temperature, number of washing cycles, and $\mathrm{pH}$ value of washing water do increase.

Moreover, the analysis also showed that an increase in the temperature or the number of washing cycles makes the effect of $\mathrm{pH}$ value more prominent (see Figure 6).

As a final word, the $p$ values obtained for the Pearson correlation were well below 0.05 , and a positive and strong relationship between the washing devices under discussion (the Pearson correlation is within the range of 0.70 (bursting strength) to 0.926 (dimensional change) was observed, which may suggest that tergotometer can be used to test the effect of laundering parameters such as $\mathrm{pH}$, temperature, and number of washing cycles on the damage of delicate textiles.

\subsection{Washing Performance}

In this section of the work, the effect of water $\mathrm{pH}$ value on the washing performance of the wool program was investigated. To

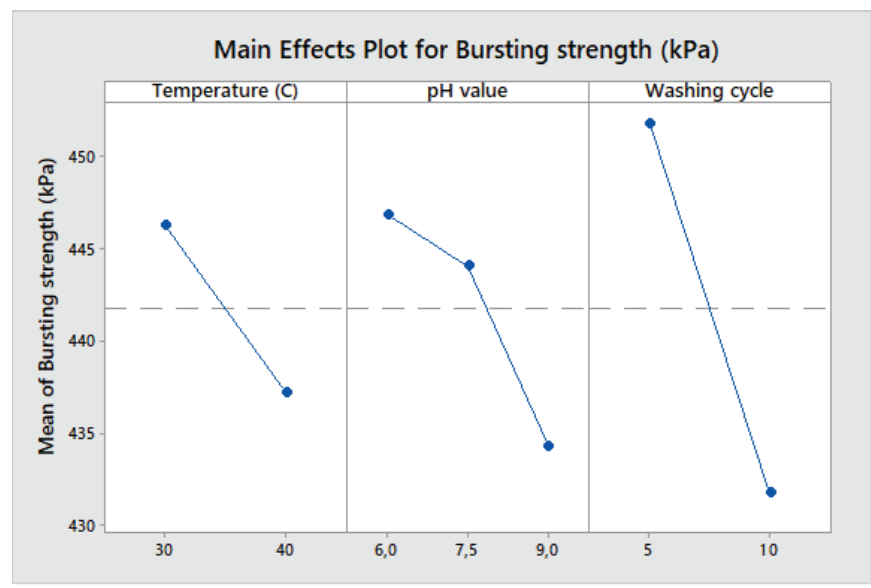

Figure 6. Main effects plot for bursting strength

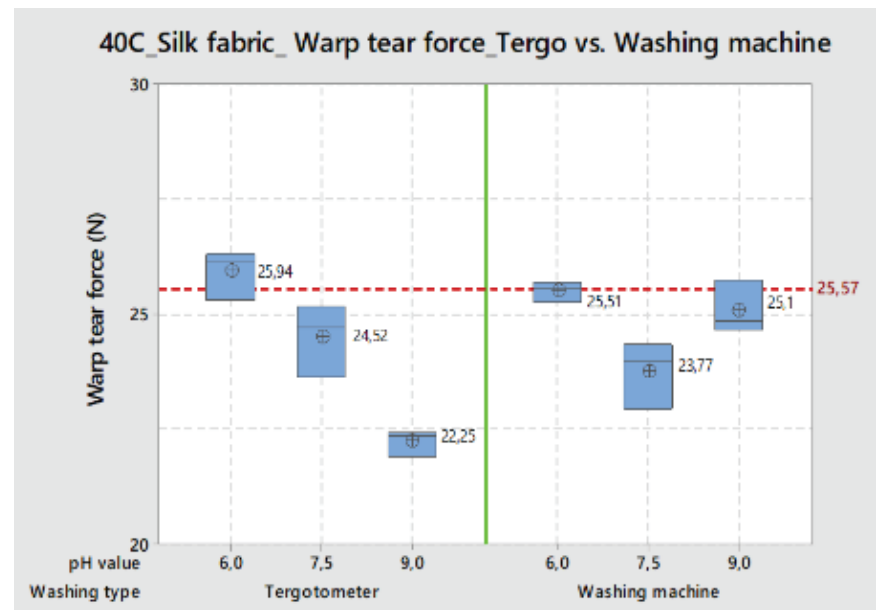

B. Woven silk fabric

Figure 5. Tearing strength of (a) woven wool fabric, (b) woven silk fabric in warp direction after 5 washes at $40^{\circ} \mathrm{C}$ in tergotometer versus washing machine 


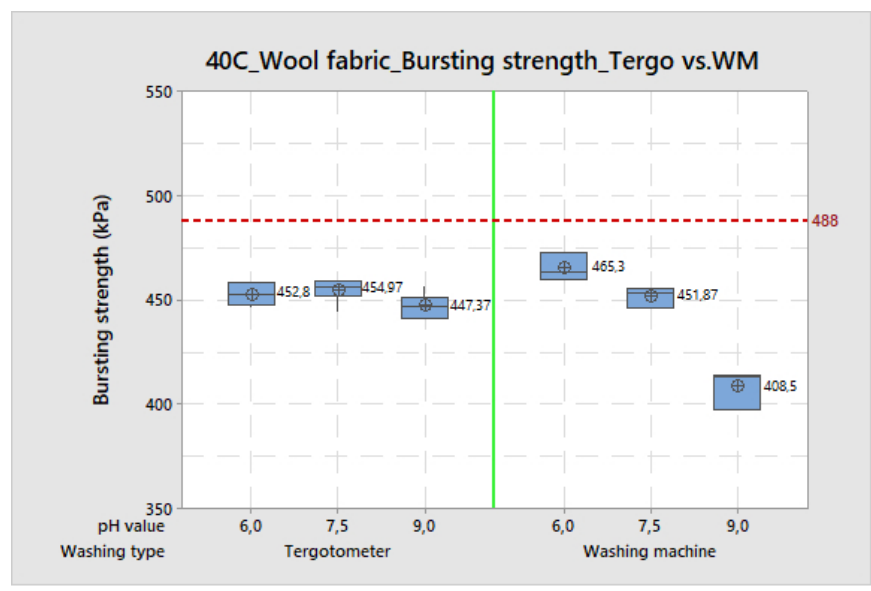

Figure 7. Bursting strength of knitted wool fabric, after 5 washes at $40^{\circ} \mathrm{C}$ in tergotometer versus washing machine

do so, the wool-stained test strips were washed in the woolen program at $40^{\circ} \mathrm{C}$. The water $\mathrm{pH}$ values were selected as 6 and 7.5. This was mainly because the experimental study revealed that the textile damage is much less at the water $\mathrm{pH}$ value of 6. The $\mathrm{pH} \mathrm{7.5,} \mathrm{however,} \mathrm{was} \mathrm{taken} \mathrm{as} \mathrm{the} \mathrm{reference} \mathrm{state} \mathrm{for}$ the domestic laundering process, as it was the value measured after adding the liquid detergent into the conditioned water. The stain removing performance was measured from tristimulus $Y$ reflectance values of the washed stain strips, with the help of a Datacolor spectrophotometer.

Figure 8 presents that the protein-based blood and chocolate milk stains performed worse at $\mathrm{pH} 6$, in comparison to $\mathrm{pH}$ 7.5. However, the non-protein-based stains such as carbon black and red wine showed almost similar performances, independent of the $\mathrm{pH}$ value of the washing medium. This is mainly because different stain types need different chemicals to remove from the textile surface. Laundry detergents contain various chemicals such as surface active agents, brighteners, enzymes, and other chemical agents to stabilization [42]. Surface active agents remove oil-based stains, and bleachers in laundry detergent remove colored stains such as red wine, coffee, and tea stains. When it comes to enzymes, which are the key element for removing protein-based stains, they have very sensitive activation conditions. One of the most important

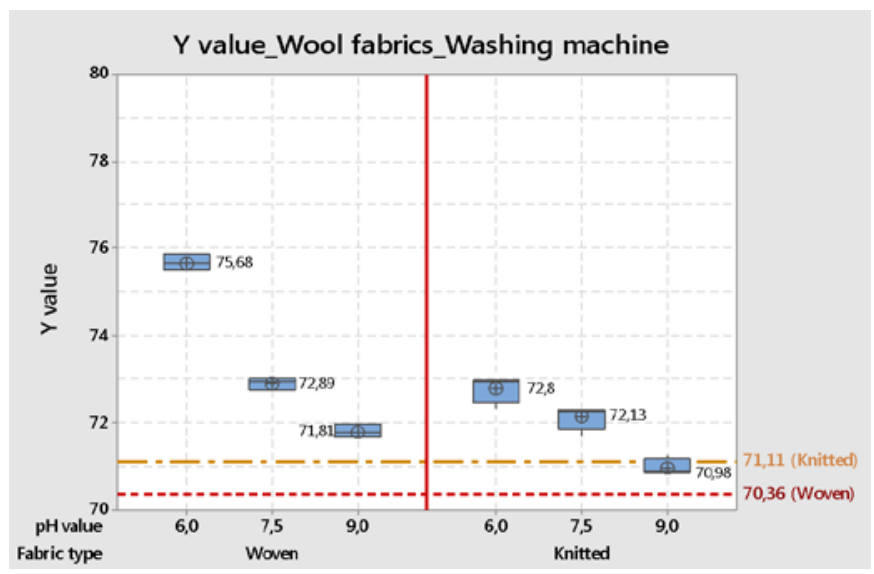

A.

Figure 9. Y Values of (a) woven and knitted wool fabric, (b) woven silk fabric after washing in domestic washing machine

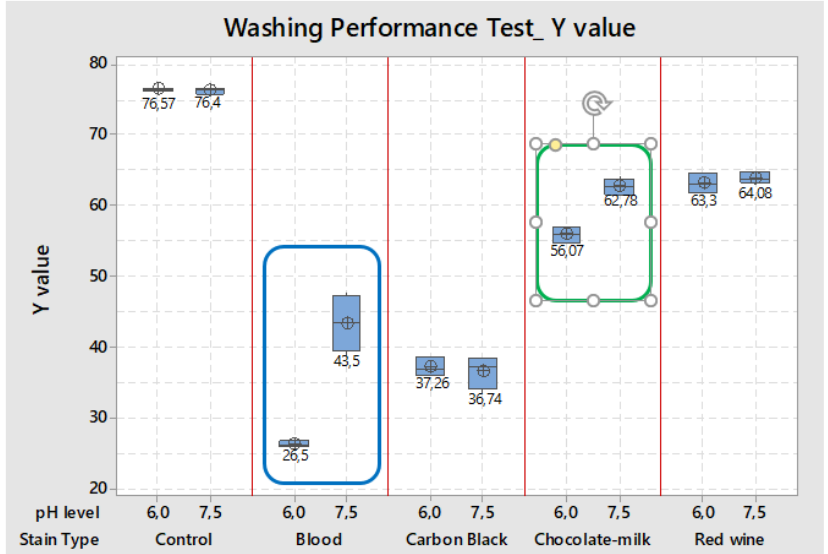

Figure 8. $Y$ values of washing performance test

parameters to enzyme activation is the $\mathrm{pH}$ level. Amylase and protease enzymes are common detergent enzymes in the laundry detergent market. These two enzymes generally have an optimum $\mathrm{pH}$ level at the alkaline region $[43,44]$. Consequently, these enzymes cannot work efficiently to remove protein-based stains at acidic $\mathrm{pH}$ values. So, at the washing water $\mathrm{pH}$ level of 6 , the washing performance of protein-based stains, which were blood stain and chocolate milk stain in the study, decreased dramatically compared to the other types of stains.

\subsection{Color Change}

All of the color change measurements were made using the spectrophotometer. For the samples washed using tergotometer, the color change measurements were repeated after the first, fifth, and tenth laundering cycle, whereas for the samples treated using the washing machine, they were made after the fifth cycle only. The $Y$ value of the knitted wool and woven wool fabric increased at $\mathrm{pH} 6$ and $\mathrm{pH} 7.5$ conditions of the tergotometer trials. However, at $\mathrm{pH} 9$ condition, the $\mathrm{Y}$ values of both the knitted and woven fabric did not change significantly.

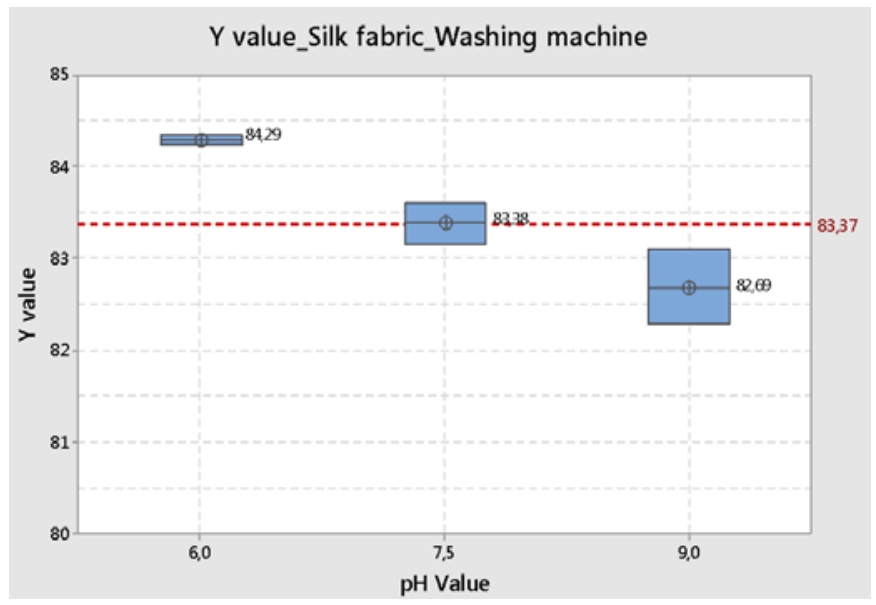

B. 
Similar to the tergotometer test results, the $Y$ values of the knitted and woven wool fabrics for domestic washing machine tests increased at $\mathrm{pH} 6$ and $\mathrm{pH} 7.5$ conditions. Moreover, for both knitted and woven fabrics, no specific change was observed at $\mathrm{pH} 9$ condition.

The $Y$ values of the silk sample were similar for all of the tergotometer and domestic washing machine trials. Irrespective of the washing device used (i.e., tergotometer and washing machine), the color change measurements had a similar tendency for the knitted and woven samples at the end of the fifth washing cycle (see Figure 9).

\section{Conclusions}

The study under discussion was conducted to systematically examine the influence of water $\mathrm{pH}$, together with the other washing parameters, on delicate textiles' wear such as the ones from silk and wool. The most important results of the work can be given as follows:

1. Irrespective of the sample type, the number of washing cycle is the main effective parameter for dimensional change and bursting strength performance of delicate textiles.

2. In the case of dimensional stability performance of the samples, it is observed that the effect of $\mathrm{pH}$ value becomes more significant as the number of washing cycles is increased.

3. So far, as the knitted fabric samples are concerned, the water $\mathrm{pH}$ value is one of the most important parameters on bursting strength performance such that the lower the water $\mathrm{pH}$ value, the lower is the performance loss is observed. Moreover, its effect becomes more prominent as the number of washing cycles as well as water temperature are increased.

4. When it comes to washing performance, the protein-based stains such as blood and chocolate milk perform worse at a water $\mathrm{pH}$ value of 6 , in comparison to their performance at a water $\mathrm{pH}$ value of 7.5. The non-protein-based stains, however, are not influenced by the change of the water $\mathrm{pH}$ value.

5. Water $\mathrm{pH}$ value affects color change, though further work is needed to analyze the interaction mechanism.

6. Tergotometer and domestic washing machine test results suggest a strong and positive correlation in terms of the dimensional change, tear strength, and bursting strength measurements.

\section{References}

[1] Gotoh, K., Nakatani, H., \& Tsujisaka, T. (2015). Delicate laundering of textiles with application of $38 \mathrm{kHz}$ ultrasonic waves. Textile Research Journal, 85(15), 1565-1578.

[2] Han, H. R., Chung, S. E., Kim, J., \& Park, C. H. (2015). Mechanical and physicochemical contribution in removal of different soil types on cotton fabric. Textile Research Journal, 85(19), 2009-2019.

[3] Lee, A., Seo, M. H., Yang, S., Koh, J., \& Kim, H. (2008). The effects of mechanical actions on washing efficiency. Fibers and Polymers, 9(1), 101-106.

[4] Yun, C., Cho, Y., \& Park, C. H. (2017). Washing efficiency and fabric damage by beating and rubbing movements in comparison with a front-loading washer. Textile Research Journal, 87(6), 708-714

[5] Cutler W. G., Davis R. C. (1972). Detergency: Theory and testmethods. New York: Marcel Dekker, p.237

[6] Mercadé-Prieto, R., Bakalis, S. (2013). Washing simulator rig to study the effect of abrasion on the removal of soils from fabrics. Tribology Letters, 52(2), 175-183.

[7] Mercade-Prieto R., Bakalis S. (2014) Methodological study on the removal of solid oil and fat stains from cotton fabrics using abrasion. Text Res J; 84: 52-65

[8] Löwendahl, R., Åsnes, H. (1972). Laundering conditions for Improved wash-and-wear appearance. Textile Research Journal, 42(7), 404-409.

[9] Morris, M., Prato, H. (1982). The effect of wash temperature on removal of particulate and oily soil from fabrics of varying fiber content. Textile Research Journal, 52(4)

[10] Park, S., Yun, C., Kim, J., Park, C. H. (2013). The effects of the fabric properties on fabric movement and the prediction of the fabric movements in a front-loading washer. Textile Research Journal, 83(11), 1201-1212.

[11] St. Laurent, J., De Buzzaccarini, F., De Clerck, K., Demeyere, H., Labeque, R., Lodewick, R., Van Langenhove, L. (2007), Laundry cleaning of textiles. In I. Johansson \& P. Somasundaran (Eds.), Handbook for cleaning/decontamination of surfaces (pp. 57-102). Amsterdam, Netherlands: Elsevier Science.

[12] Yun C., Park S., Park C.H. (2013). The effect of fabric movement on washing performance in a front-loading washer. Text Res J; 83: 1786-1795.

[13] Yun, C., Park, C. H. (2015). The effect of fabric movement on washing performance in a front-loading washer II: Under various physical washing conditions. Textile Research Journal, 85(3), 251-261.

[14] Paul R (Ed.), (2015). Functional Finishes for Textiles, Chapter 6: Commercial shrink-resist finishes for wool. Elsiver Ltd.

[15] Ma, M., You, L., Chen, L., Zhou, W. (2014). Effects of ultrasonic laundering on the properties of silk fabrics. Textile Research Journal, 84(20), 2166-2174.

[16] Schlink, A. C., Greeff, J. C., Ehni, J., Denning, R. (2009). Using a benchtop rotor spinning system to measure variation between individual fleeces for predicting yarn and fabric characteristics. Animal Production Science, 49(4), 333-339. 
[17] Fan, J., \& Hunter, L. (2009). Engineering apparel fabrics and garments. In J. Fan, \& L. Hunter (Eds.), Chapter 13: Laundry performance of fabrics and garments (pp. 339 and 341-343). Woodhead Publishing (England).

[18] Quaynor, L., Nakajima, M., Takahashi, M. (1999). Dimensional changes in knitted silk and cotton fabrics with laundering. Textile Research Journal, 69(4), 285-291.

[19] Quaynor, L., Takahashi, M., Nakajima, M. (2000). Effects of laundering on the surface properties and dimensional stability of plain knitted fabrics. Textile Research Journal, 70(1), 28-35.

[20] Algie, J. E., Baird, K., Foulds, R. A., Robinson, V. N. (1974). The felting of wool fabrics washed at various values of $\mathrm{pH}$, and the isoelectric point determined by streaming potential measurements. Textile Research Journal, 44(10), 767771.

[21] Van Amber, R. R., Niven, B. E., Wilson, C. A. (2010). Effects of laundering and water temperature on the properties of silk and silk-blend knitted fabrics. Textile Research Journal, 80(15), 1557-1568.

[22] Feldtman H. D., McPhee J. R., (1966). The Effect of Detergents on the Felting of Wool, Textile Res. Jou, Volume: 36 issue: 1, page(s): 48-55, 48-55

[23] Bloomfield, S. F., Exner, M., Signorelli, C., Scott, E. A. (2013). Effectiveness of laundering processes used in domestic (home) settings. International Scientific Forum on Home Hygiene.

[24] Bloomfield, S. F., Carling, P. C., Exner, M. (2017). A unified framework for developing effective hygiene procedures for hands, environmental surfaces and laundry in healthcare, domestic, food handling and other settings. GMS Hygiene and Infection Control, 12, Doc08.

[25] Bockmühl, D. P. (2017). Laundry hygiene-how to get more than clean. Journal of Applied Microbiology, 122(5), 11241133.

[26] Honisch, M., Stamminger, R., Bockmühl, D. P. (2014). Impact of wash cycle time, temperature and detergent formulation on the hygiene effectiveness of domestic laundering. Journal of Applied Microbiology, 117(6), 17871797.

[27] Abeliotis, K., Amberg, C., Candan, C., Ferri, A., Osset, M., Owens, J., \& Stamminger, R. (2015). Trends in laundry by 2030. Household and Personal Care Today, 10, 22-28.

[28] Arai, H. (1966). Study of detergency. I. Effect of the concentration and the kind of detergent in hard water. Journal of the American Oil Chemists' Society, 43(5), 312314.

[29] Brown, D. M., Cameron, B. A., Meyer, S. S., \& Umber, J. J. (1991). The effects of water hardness level on washing quality using commercial laundry detergents. Journal of Consumer Studies and Home Economics, 15(3), 215-222.
[30] Cameron, B. A. (2007). Laundering in cold water: Detergent considerations for consumers. Family and Consumer Sciences Research Journal, 36(2), 151-162.

[31] Cameron, B. A. (2011). Detergent considerations for consumers: Laundering in hard water-how much extra detergent is required. Journal of Extension, 49, 1-11.

[32] Cameron, B. A., \& Brown, D. M. (1995). A survey of commercial laundry detergents - how effective are they?: Part III: Powders, liquids and hard water. Journal of Consumer Studies and Home Economics, 19(1), 85-97.

[33] Gotoh, K., Horibe, K., Mei, Y., \& Tsujisaka, T. (2016). Effects of water hardness on textile detergency performance in aqueous cleaning systems. Journal of Oleo Science, 65(2), 123-133.

[34] Kaşıkçı, N. 2016. Improving inlet water quality for washing machine by using electrochemical application, (Master Thesis). Istanbul Technical University, Graduate School of Science Engineering and Technology, Istanbul.

[35] Nagarajan, M. K., \& Paine, H. L. (1984). Water hardness control by detergent builders. Journal of the American Oil Chemists' Society, 61(9), 1475-1478.

[36] Qing, L., Brady, P. R., \& Xungai, W. (2009). The effect of $\mathrm{pH}$ on wool fiber diameter and fabric dimensions. Textile Research Journal, 79(10), 953-957.

[37] Umber, J. J., Brown, D. M., Cameron, B. A., Meyer, S. S., Powell, J. A., \& Sisco, B. R. (1992). The effect of water hardness on washing performance of built and unbuilt surfactants. Journal of Consumer Studies and Home Economics, 16(2), 151-159.

[38] Ferri, A., Osset, M., Abeliotis, K., Amberg, C., Candan, C., Owens, J., \& Stamminger, R. (2016). Laundry performance: Effect of detergent and additives on consumer satisfaction. Tenside Surfactants Detergents, 53(4), 375-386.

[39] Carr, C. (Ed.), (1995)., Chemistry of The Textiles Industry, Chapter 4: Physical and chemical effects of domestic laundering processes, D.P. BISHOP, pp 126-172,

[40] EN 60456:2019. Clothes washing machines for household use - Methods for measuring the performance.

[41] Kymäläinen, H.-R. (2007). Comparison of the washing efficiencies of a laboratory washing device (launderometer) and of automatic household washing machines with horizontal drums. International Journal of Consumer Studies, 31(6), 565-570.

[42] Smulders, E., \& Rahse, W. (2002). Laundry detergents. Weinheim, Germany: Wiley-VCH, Weinheim.

[43] Banik, R., Prakash, M. (2004). Laundry detergent compatibility of the alkaline protease from Bacillus cereus. Microbiological Research, 159(2), 135-140.

[44] Niyonzima, F., More, S. (2014). Detergent-Compatible Bacterial Amylases. Applied Biochemistry And Biotechnology, 174(4), 1215-1232. 